(c) 2017, THE AUTHORS. Published by FASS and Elsevier Inc. on behalf of the American Dairy Science Association ${ }^{\circledR}$.

This is an open access article under the CC BY-NC-ND license (http://creativecommons.org/licenses/by-nc-nd/3.0/).

\title{
Validation of genomic predictions for wellness traits in US Holstein cows
}

\author{
Anthony K. McNeel, Brenda C. Reiter, Dan Weigel, Jason Osterstock, and Fernando A. Di Croce ${ }^{1}$ \\ Zoetis Genetics, 333 Portage Street, Kalamazoo, Ml 49007
}

\begin{abstract}
The objective of this study was to evaluate the efficacy of wellness trait genetic predictions in commercial herds of US Holstein cows from herds that do not contribute phenotypic information to the evaluation. Tissue samples for DNA extraction were collected from more than 3,400 randomly selected pregnant Holstein females in 11 herds and 2 age groups (69\% nulliparous, $31 \%$ primiparous) approximately 30 to $60 \mathrm{~d}$ before their expected calving date. Lactation records from cows that calved between September 1, 2015, and December 31,2015 , were included in the analysis. Genomically enhanced predicted transmitting abilities for the wellness traits of retained placenta, metritis, ketosis, displaced abomasum, mastitis, and lameness were estimated by the Zoetis genetic evaluation and converted into standardized transmitting abilities. Mean reliabilities of the animals in the study ranged between 45 and $47 \%$ for each of the 6 traits. Animals were ranked by their standardized transmitting abilities within herd and age group then assigned to 1 of 4 groups of percentilebased genetic groups of equal size. Adverse health events, including retained placenta, metritis, ketosis, displaced abomasum, mastitis, and lameness, were collected from on-farm herd management software, and animal phenotype was coded as either healthy (0), diseased (1), or excluded for each of the 6 outcomes of interest. Statistical analysis was performed using a generalized linear mixed model with genetic group, age group, and lactation as fixed effects, whereas herd and animal nested within herd were set as random effects. Results of the analysis indicated that the wellness trait predictions were associated with differences in phenotypic disease incidence between the worst and best genetic groups. The difference between the worst and best genetic groups in recorded disease incidence was $2.9 \%$ for retained placenta, $10.8 \%$ for metritis, $1.1 \%$ for displaced abomasum, $1.7 \%$ for ketosis, $7.4 \%$ for mastitis, and $3.9 \%$ for lameness. Odds ratio estimates between the highest and lowest genetic groups ranged
\end{abstract}

Received November 17, 2016.

Accepted July 18, 2017.

${ }^{1}$ Corresponding author: fernando.dicroce@zoetis.com from 1.6 (lameness) to 17.1 (displaced abomasum) for the 6 traits analyzed. These results indicate that wellness trait information of young calves and heifers can be used to effectively predict meaningful differences in future health performance. Improving wellness traits through direct genetic selection presents a compelling opportunity for dairy producers to help reduce disease incidence and improve profitability when coupled with sound management practices.

Key words: Holstein, health, mastitis, genomics

\section{INTRODUCTION}

Genetic evaluation and selection in dairy cattle has primarily focused on yield traits such as milk, fat, and protein production. Over the course of the last $30 \mathrm{yr}$, researchers at the USDA Animal Genome Improvement Laboratory (Beltsville, MD) have added to the production traits by developing national genetic evaluations for indirect health predictions including linear SCC (Schutz, 1994), productive life (VanRaden and Klaaskate, 1993), livability (Miller et al., 2008), and daughter pregnancy rate (Kuhn et al., 2004). These indirect health predictions are currently available from the Council on Dairy Cattle Breeding (CDCB), and evidence exists that these traits elicit some genetic improvement for resistance to adverse health events (e.g., metritis, displaced abomasum) via correlated response (Vukasinovic et al., 2017). However, presumably as a result of current management practices and the genetic antagonisms between adverse health events and production traits, the incidence of many common diseases in contemporary dairy production systems within the United States continued to increase (Jones et al., 1994; Lucy, 2001; APHIS, 2009). As a result, dairy cows today are generally considered to be less robust than previous generations.

The decline in the health and wellness of dairy animals led to a growing interest in the use of genetic improvement as part of a comprehensive health management strategy for dairy cows (Weigel et al., 1998; Heriazon et al., 2013; Thompson-Crispi et al., 2014). Producer-recorded health events have been successfully used by researchers to identify genetic differences between dairy sires in daughter susceptibility to common 
health disorders, including, but not limited to, metritis, displaced abomasum, and mastitis (Zwald et al., 2004, 2006; Neuenschwander et al., 2012; Parker Gaddis et al., 2014). When coupled with sound management practices, genetic improvement programs that incorporate direct assessment of genetic risk for adverse health events have the potential to improve animal well-being and the financial viability of the dairy by reducing culling rates, veterinary expenses, labor requirements, and discarded milk (Parker Gaddis et al., 2014). Reducing the incidence of these adverse health events can help to improve profitability, as the economic impact of these adverse health events is estimated to range between $\$ 203$ for a case of ketosis to $\$ 438$ per case of displaced abomasum (Gaurd, 2009).

In response to industry needs for genetic improvement of dairy wellness traits, and in collaboration with the US Holstein Association (Brattleboro, VT), researchers at the University of Georgia-Athens, and commercial dairy producers; Zoetis Genetics developed a dairy cattle genetic and genomic evaluation to estimate genetic risk for 6 health events in US Holstein dairy cattle (Vukasinovic et al., 2017). Conveyed as a standardized transmitting ability (STA), the wellness trait predictions include genomically enhanced genetic predictions for retained placenta, metritis, ketosis, displaced abomasum, mastitis, and lameness. The development of this genetic evaluation, including a description of the phenotypes, statistical model, generation of the genomically enhanced predicted transmitting abilities (gPTA), and reliabilities have been reported previously (Vukasinovic et al., 2017). This wellness trait genetic evaluation system uses single-step best linear unbiased prediction (BLUPF90) to estimate an animal's genetic risk to experience these 6 health events. Single-step BLUPF90 simultaneously incorporates multiple sources of data (phenotypes, pedigree, and genotypes) to minimize bias, improve the computational efficiency of the genetic evaluation, and increase the timeliness of the genetic predictions for experiencing the health events (Misztal et al., 2009, 2013, 2014).

An accepted best practice in any genetic evaluation or predictive algorithm is to evaluate the association of the genetic predictions with the observed performance of the evaluated animals in an external population. For that reason, a multiyear validation study was conducted to evaluate the efficacy of the genomically enhanced genetic predictions for wellness traits in US Holstein cows. This study was conducted using US Holstein cows managed in herds that do not contribute phenotypes to the genetic evaluation. The objective of our study was to demonstrate the ability of wellness trait predictions to accurately predict disease incidence using herds that do not contribute phenotypes to the genetic evaluation. In the current study, we hypothesized that animals with the highest genetic risk for the wellness traits would have a higher phenotypic incidence than animals with the lowest genetic risk through 305 DIM.

\section{MATERIALS AND METHODS}

\section{Experimental Design}

A power calculation was conducted to determine the size of the population necessary to detect a statistically significant difference in the disease incidence between 2 genetic groups where the difference in incidence is $20 \%$ of the mean of the population. The maximum number of animals per herd was limited to 350 with an $\alpha$ of 0.05 and a $\beta$ of 0.8 , according to the methodology described previously (Dohoo et al., 2009). This study was powered to have an $80 \%(\beta)$ probability of detecting a significant difference at the $0.05(\alpha)$ level if the true differences were at least $20 \%$ between the contrasted genetic groups. Power calculations were conducted for all 6 health events, and the health event requiring the largest population was used as the target sample size. The power calculations estimated that a population of 3,000 animals would be sufficient to detect statistically significant differences in phenotypic incidence of $20 \%$ between 2 genetic groups for all 6 health events.

\section{Phenotypic Data}

Herds, Animals, and Study Duration. Eleven large herds (average 4,180 lactating cows) distributed across the major dairy-producing regions of the United States were enrolled in this study based on 4 criteria: (1) did not contribute phenotypic data to the Zoetis genetic evaluation for wellness traits, (2) recorded health events at an incidence similar to the national incidence in the wellness trait genetic evaluation for at least 5 of the 6 health events (Vukasinovic et al., 2017), (3) were not applying selection pressure (e.g., heifer culling) based on genomically enhanced genetic predictions, and (4) were of sufficient size to have at least 200 first parity and 100 second parity projected calving events between September 1 and December 31, 2015. Animals in first parity in 2015 (age group A) and second parity in 2015 (age group B) were selected for our study, as these age groups represent the majority of lactating animals on US dairies. Enrolling multiple age groups in the study afford the opportunity to quantify the potential effects of selection bias in the first lactation on the genetic predictions and phenotypic incidence. 
From these 11 herds, lists of first- and second-parity Holstein cows with a projected calving date between September 1 and December 31, 2015, were exported from the herd management software. A subset of animals were then randomly selected from these lists of eligible heifers or cows within herd and age group using the sample function of $\mathrm{R}$ (R Core Team, 2015), and a tissue sample (ear notch puncture) was collected for genetic testing. In total, 3,462 animals were sampled from these 11 herds and all samples were put through the CDCB genetic evaluation to ensure compatibility with animal identification (ID), parentage, and breed (e.g., genomic breed composition $\geq 87.5 \%$ Holstein).

In the study population, incorrect sire data were submitted for $17.5 \%$ of the animals $(606 / 3,462)$ and, along with maternal grandsire parentage, was corrected for all animals in the study when possible. Sire of record was not submitted for $33.3 \%$ of the animals $(1,143 / 3,462)$. Of these animals, 873 subsequently had a sire identified by the CDCB. Bulls without a genotype at the CDCB, assumed to be herd bulls, sired $7.8 \%(270 / 3,462)$ of the animals sampled in this study.

Removal of animals from the study occurred for at least 1 of the following reasons per animal: calving outside the desired calving window (532), animal was identified as less than $87.5 \%$ Holstein by the CDCB (57), DNA marker call rates were of questionable integrity (51), the animal was sold or died before entering production (18), restrictions on correcting registered pedigree (7), or genotype had previously been submitted under a different unique ID (3). These exclusion criteria narrowed the study population of animals from 3,462 to 2,875 Holstein cows (1,988 first parity; 887 second parity) contributing lactation records to this analysis.

Phenotypic Data Collection and Editing. The herds were not routinely monitored or compensated for health event recording by Zoetis. For this study, lactation events occurring before August 24, 2016, and through 305 DIM were included in the analysis. Health events including retained placenta, metritis, ketosis, displaced abomasum, mastitis, and lameness were col- lected from on-farm herd management software. Terminology used to record the health events varied across the enrolled farms, which were later standardized during processing of the lactation records (Table 1).

Health events occurring before freshening, along with retained placenta and metritis events occurring after 50 DIM, were removed from the data set to minimize the effect of recording errors and nontransition-related events (i.e., abortions). Duplicate events by unique animal ID and lactation were removed from the data set. In an effort to minimize the potential for overestimation of the healthy lactation records, a DIM threshold was used to assess when a lactation record accumulated sufficient DIM for nonaffected records to be considered healthy. These thresholds were the DIM by which $90 \%$ of cases were recorded, represented by 3 DIM for retained placenta, 9 DIM for metritis, 16 DIM for ketosis, 66 DIM for displaced abomasum, 250 DIM for mastitis, and 265 DIM for lameness (Table 2). Those lactation records which surpassed these DIM thresholds without an incidence of the health event were then considered healthy.

These data-editing rules were applied to lactation records for the enrolled animals $(\mathrm{n}=2,875)$ and individual lactation records were assigned to 1 of 3 possible phenotypes for each health event.

- Healthy $(0)=$ no documented incidence of the health event through 305 DIM and DIM exceeded the $90 \%$ DIM threshold.

- Diseased $(1)=$ a documented incidence of the health event through 305 DIM regardless of how many times the animal was diagnosed with the health event during the lactation. Thus, cows with 1 case of mastitis and 3 cases of mastitis are both recorded as a 1.

- Excluded (.) = lactation record where the animal had not experienced the health event and the number of DIM did not surpass the 90\% DIM threshold (e.g., animal was sold, died, or did not have sufficient DIM to surpass the 90\% DIM threshold to be considered "healthy").

Table 1. Standardization of on-farm codes used to record the 6 health events analyzed in this study

\begin{tabular}{lll}
\hline Health event & $\begin{array}{l}\text { Standardized } \\
\text { abbreviation }\end{array}$ & Farm term \\
\hline Retained placenta & RETP & RETP, RP, RETAINP, RETPLACENT, RET PLACENT, RET_PLACEN \\
Metritis & METR & METR, METRHR, MET, UTERUS, PYO, METRITIS \\
Ketosis & KETO & KETOSIS, KETO \\
Displaced abomasum & DA & DA, LDA, RDA, LDA/RDA \\
Mastitis & MAST & MAST, MASTITIS, EXTMAST, EXMAST2, MAST., MAST.RR, MAST.RF, MAST.LR, \\
Lameness & MAST.LF, HMAST \\
\hline
\end{tabular}


Table 2. The DIM by which $90 \%$ of health events were recorded, the average disease incidence (percentage of fresh cows affected) for first and second lactation in the enrolled herds, and previously published economic cost per case with corresponding citations are also provided

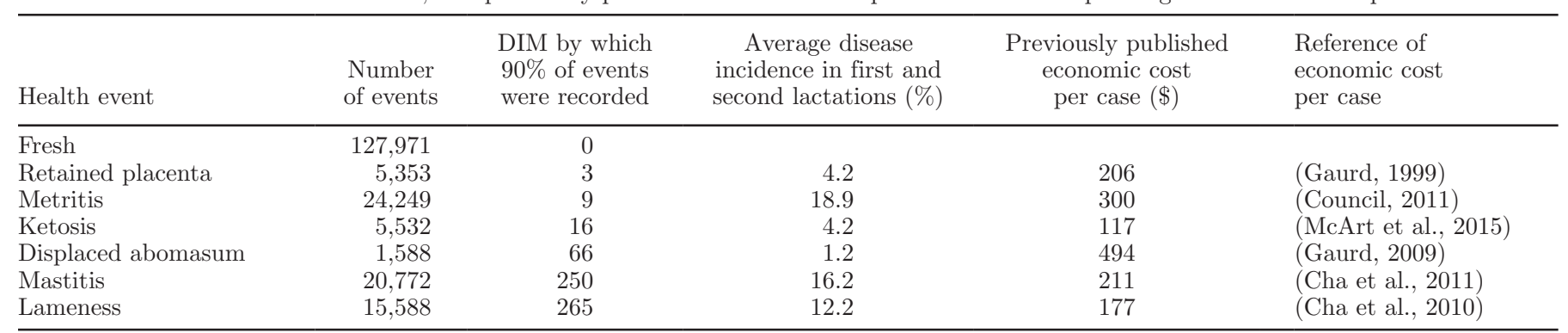

\section{Evaluation of Genetic Merit}

Genotyping, Genetic Evaluation, and Assigning Animals to Genetic Groups. Tissue samples from a random subset animals from the 11 herds were genotyped with Zoetis low-density chips by the Zoetis Genetics Laboratory in Kalamazoo, Michigan. Animals were nominated, along with pedigree and genotype, to the CDCB to obtain CDCB genetic evaluation predictions. Low-density genotypes $(6-19 \mathrm{~K}$ markers) were imputed up to 45,425 markers using FImpute (Sargolzaei et al., 2014). Previously described gPTA and reliabilities (Vukasinovic et al., 2017) were then estimated using the single step evaluation method (Misztal et al., 2009, Misztal et al., 2013) per the standard procedure in the genetic evaluation for wellness traits (Clarifide Plus, Zoetis). The reliabilities of EBV were approximated using the program accf90GS, which implements an algorithm that combines contributions of genotypes, pedigree, and phenotypes (Misztal et al., 2013).

Genomically enhanced PTA were converted into STA using the equation

$$
\mathrm{STA}=\{[(\mathrm{gPTA}-\mu) / \sigma] \times-5\}+100
$$

with $\mu$ representing the mean gPTA of the genetic evaluation population and $\sigma$ representing the gPTA standard deviation of the genetic evaluation population. The means and standard deviations of the wellness traits predictions were derived from a subset of genotyped animals $(\mathrm{n}=76,840)$ in the genetic evaluation. For wellness trait predictions, a value of 100 represents the average expected disease risk, with the standard deviation equation to 5 . Standardized transmitting abilities greater than 100 represent lower expected average disease risk relative to a base population. Higher STA values are more desirable for all traits; thus, selecting for a higher STA will apply selection pressure for reduced genetic risk of disease.

Wellness trait predictions (STA) were used to rank and assign cows to a percentile-based disease risk groups (genetic groups: bottom 25, 26-50, 51-75, and top $25 \%$ ) within herd and age group for each of the 6 wellness trait predictions to account for the lack of independence between animal, age group, and herd; similar to what has been reported by others (Weigel et al., 2012).

Estimating Connectivity Between the Study and Genetic Evaluation Populations. The relationship between the study population and the genetic evaluation population was calculated using the diagonal of the genomic relationship matrix $(\mathbf{G})$ that is generated as part of the genetic evaluation (Vukasinovic et al., 2017).

Estimating Cost per Cow for Each Health Trait. The average cost per cow was derived using previously published estimates of disease cost per case (Table 2) and the equation

$$
\text { Cost per cow }=\mu \times \text { cost per case, }
$$

where $\mu$ represents the marginal mean for the genetic group and the cost is the selected published economic cost estimate per case of the adverse health event (Gaurd, 1999, 2009; Cha et al., 2010, 2011; Dairy Cattle Reproduction Council, 2011; McArt et al., 2015).

\section{Statistical Analysis}

The data analysis for this paper was generated using SAS software (version 9.3, SAS Institute Inc., Cary, NC; SAS, 2011). For all analyses, differences were considered to be statistically significant when $P<0.05$. Medians, standard deviations, minimums, and maximums were calculated using PROC MEANS in SAS 9.3.

For this study, the dependent variable was the incidence of the health event in the study population, where incidence was defined as the number or proportion of adverse health events per lactation. Repeated observations measured on animals (first and second lactation records) were used in the statistical analysis. 
The binary health events $(0,1)$ were analyzed using PROC GLIMMIX with a binomial distribution and a logit link function in SAS 9.3 using the statistical model

$$
\mathbf{Y}=\mathbf{X} \beta+\mathbf{Z} \mu+\mathrm{e}
$$

where $\mathbf{Y}$ represents the vector of the phenotype; $\beta$ represents the fixed effects of the genetic group (worst $25 \%, 26-50 \%, 51-75 \%$, best $25 \%$ ), interaction between lactation record $(1,2)$, and age group at the start of the study (age group A, age group B); $\mu$ represents the random effects of animal nested within herd and herd to account for repeated measures; and e represents the residual, with $\mathbf{X}$ and $\mathbf{Z}$ representing design matrices relating observations $\mathbf{Y}$ to $\beta$ and $\mu$, respectively. Marginal means, the standard error of the mean, the odds ratio, and the $95 \%$ confidence interval are reported.

\section{RESULTS AND DISCUSSION}

The observed results demonstrate the ability of wellness trait predictions to accurately predict disease prevalence in first and second lactation. These results indicate that genomically enhanced wellness trait predictions for young calves can be used to effectively pre- dict future health performance. Reducing the incidence of these adverse health events through direct genetic selection can play an important role in a comprehensive health management strategy for dairy cows through early selection of replacement heifers.

\section{Incidence of Health Events for the Genetic Groups}

Differences in disease incidence (marginal means) were statistically significant between the genetic groups for retained placenta $(P=0.0003)$, metritis $(P$ $<0.0001)$, displaced abomasum $(P=0.0014)$, ketosis $(P=0.0017)$, mastitis $(P \leq 0.0001)$, and lameness $(P$ $=0.0336$; Table 3 ). As shown in Table 3, the differences in disease incidence between the top and bottom quartiles was $2.9 \%$ for retained placenta, $10.8 \%$ for metritis, $1.1 \%$ for displaced abomasum, $1.7 \%$ for ketosis, $7.4 \%$ for mastitis, and $3.9 \%$ for lameness (Table $3)$. Previously published disease economic costs demonstrate that the differences in marginal means by genetic groups (disease incidence) translate into appreciable differences in expected economic costs on a US dairy operation (Table 3).

The estimated economic costs per cow to date for the individual health events within each genetic group

Table 3. Least squares means, disease incidence (marginal means), SEM of the genetic groups when animals are ranked by standardized transmitting abilities (STA), and estimated disease cost per cow for retained placenta (RETP-STA), metritis (METR-STA), ketosis (KETOSTA), displaced abomasum (DA-STA), mastitis (MAST-STA), and lameness (LAME-STA)

\begin{tabular}{|c|c|c|c|c|c|c|c|c|c|}
\hline Trait & $\begin{array}{l}\text { STA } \\
\text { percentile } \\
\text { group }\end{array}$ & df & $\begin{array}{c}\text { Disease incidence } \\
\text { (marginal mean, \%) }\end{array}$ & $\begin{array}{c}\text { SEM } \\
(\%)\end{array}$ & $P$-value & $\begin{array}{l}\text { Disease } \\
\text { cost per } \\
\text { cow }(\$)\end{array}$ & $\begin{array}{l}95 \% \text { CI } \\
\text { lower } \\
\text { limit }\end{array}$ & $\begin{array}{l}\text { Odds } \\
\text { ratio }\end{array}$ & $\begin{array}{c}95 \% \text { CI } \\
\text { upper } \\
\text { limit }\end{array}$ \\
\hline \multirow[t]{4}{*}{ RETP-STA } & Bottom 25 & 878 & $4.52^{\mathrm{a}}$ & 1.55 & \multirow[t]{4}{*}{0.0003} & 9.30 & 1.742 & 2.943 & 4.973 \\
\hline & $26-50$ & & $3.34^{\mathrm{ab}}$ & 1.19 & & 6.88 & 1.245 & 2.150 & 3.710 \\
\hline & $51-76$ & & $2.48^{\mathrm{bc}}$ & 0.92 & & 5.10 & 0.893 & 1.580 & 2.799 \\
\hline & Top 25 & & $1.58^{\mathrm{c}}$ & 0.63 & & 3.26 & - & - & - \\
\hline \multirow[t]{4}{*}{ METR-STA } & Bottom 25 & 873 & $23.64^{\mathrm{a}}$ & 4.65 & \multirow[t]{4}{*}{$<0.0001$} & 70.92 & 1.671 & 2.098 & 2.635 \\
\hline & $26-50$ & & $18.49^{\mathrm{b}}$ & 3.91 & & 55.47 & 1.219 & 1.537 & 1.940 \\
\hline & $51-76$ & & $19.14^{\mathrm{b}}$ & 4.01 & & 57.42 & 1.273 & 1.605 & 2.023 \\
\hline & Top 25 & & $12.86^{\mathrm{c}}$ & 2.94 & & 38.58 & - & - & - \\
\hline \multirow[t]{4}{*}{ KETO-STA } & Bottom 25 & 787 & $3.20^{\mathrm{a}}$ & 1.98 & \multirow[t]{4}{*}{0.0017} & 3.75 & 1.400 & 2.202 & 3.464 \\
\hline & $26-50$ & & $2.45^{\mathrm{ab}}$ & 1.53 & & 2.87 & 1.048 & 1.671 & 2.663 \\
\hline & $51-76$ & & $1.68^{\mathrm{bc}}$ & 1.07 & & 1.97 & 0.697 & 1.139 & 1.862 \\
\hline & Top 25 & & $1.48^{\mathrm{c}}$ & 0.95 & & 1.73 & - & - & - \\
\hline \multirow[t]{4}{*}{ DA-STA } & Bottom 25 & 694 & $1.13^{\mathrm{a}}$ & 0.68 & \multirow[t]{4}{*}{0.0014} & 5.58 & 2.237 & 17.051 & 129.954 \\
\hline & $26-50$ & & $0.47^{\mathrm{ab}}$ & 0.32 & & 2.32 & 0.868 & 7.127 & 58.542 \\
\hline & $51-76$ & & $0.13^{\mathrm{b}}$ & 0.12 & & 0.64 & 0.175 & 1.950 & 21.719 \\
\hline & Top 25 & & $0.07^{\mathrm{b}}$ & 0.07 & & 0.35 & - & - & - \\
\hline \multirow[t]{4}{*}{ MAST-STA } & Bottom 25 & 725 & $15.94^{\mathrm{a}}$ & 2.97 & \multirow[t]{4}{*}{$<0.0001$} & 33.63 & 1.502 & 2.032 & 2.748 \\
\hline & $26-50$ & & $11.21^{\mathrm{b}}$ & 2.27 & & 23.65 & 0.987 & 1.353 & 1.856 \\
\hline & $51-76$ & & $11.05^{\mathrm{b}}$ & 2.24 & & 23.32 & 0.969 & 1.331 & 1.856 \\
\hline & Top 25 & & $8.54^{\mathrm{c}}$ & 1.82 & & 18.00 & - & - & - \\
\hline \multirow[t]{4}{*}{ LAME-STA } & Bottom 25 & 651 & $11.43^{\mathrm{a}}$ & 3.77 & \multirow[t]{4}{*}{0.0336} & 20.23 & 1.146 & 1.578 & 2.173 \\
\hline & $26-50$ & & $8.70^{\mathrm{b}}$ & 3.98 & & 15.40 & 0.837 & 1.166 & 1.625 \\
\hline & $51-76$ & & $8.63^{\mathrm{b}}$ & 2.96 & & 15.28 & 0.829 & 1.156 & 1.610 \\
\hline & Top 25 & & $7.55^{\mathrm{b}}$ & 2.63 & & 13.37 & - & - & - \\
\hline
\end{tabular}

${ }^{\mathrm{a}-\mathrm{c}}$ Marginal means within column and trait with different superscripts differ $(P<0.05)$. 
Table 4. Descriptive statistics of genomic standardized transmitting abilities (STA) for retained placenta (RETP-STA), metritis (METR-STA), ketosis (KETO-STA), displaced abomasum (DA-STA), mastitis (MASTSTA), and lameness (LAME-STA) and reliabilities (REL) for wellness traits based on 2,875 Holstein heifers and cows with STA predictions

\begin{tabular}{llclcc}
\hline Trait & Statistic & Median & SD & Minimum & Maximum \\
\hline RETP-STA & STA & 101 & 5.31 & 79 & 114 \\
& REL & 0.48 & 0.05 & 0.25 & 0.59 \\
METR-STA & STA & 101 & 5.11 & 79 & 114 \\
& REL & 0.47 & 0.05 & 0.24 & 0.59 \\
KETO-STA & STA & 101 & 5.3 & 69 & 113 \\
& REL & 0.48 & 0.05 & 0.25 & 0.58 \\
DA-STA & STA & 101 & 4.99 & 75 & 110 \\
& REL & 0.47 & 0.05 & 0.24 & 0.58 \\
MAST-STA & STA & 100 & 5.2 & 81 & 113 \\
LAME-STA & REL & 0.48 & 0.05 & 0.25 & 0.59 \\
& STA & 100 & 5.41 & 78 & 115 \\
& REL & 0.47 & 0.05 & 0.25 & 0.58 \\
\hline
\end{tabular}

are reported in Table 3 . These economic values represent the estimated incurred cost per cow of the adverse health event by genetic group within this data set. The results of the mastitis analysis indicate that the worst genetic group of animals has incurred a cost per cow of $\$ 33.63$ compared with the $\$ 18.00$ cost per cow for the best genetic group when only the first case per lactation is considered. The cost per case of mastitis of $\$ 211$ estimated by Cha et al. (2011) includes milk and fertility losses as well as treatment and culling costs. The $\$ 16$ per cow differential between the worst and best genetic groups is a testament to the large potential economic impact of selecting for a higher mastitis STA. These economic costs are a preliminary estimate of how much an average dairy producer could expect to lose per cow within a genetic group with a similar parity structure ( $\sim 2 / 3$ first lactation, $\sim 1 / 3$ second lactation). As these estimates are calculated using only phenotypic data from the first and second lactation, economic costs incurred through the third lactation will provide greater insight on the economic impact of these predictions for the animal's time in the herd.

Although, significant differences in the incidence of the health events by genetic group were detected, the number of animals included in the analysis was less than what was indicated as necessary by the power analysis $(2,875$ vs. 3,000$)$. The minimum number (n $=3,000$ ) required by the power analysis was to detect a significant difference of $20 \%$ difference in lameness. Despite this smaller study population, a significant difference of $33 \%$ reduction in lameness incidence was observed, which compensated for the higher than anticipated exclusion of animals detailed in the materials and methods. The proportion of the sampled animals $(\sim 15 \%)$ that were subsequently excluded from this prospective study due to calving outside of the desired calving window was larger than expected. These delayed calvings could have been due to prolonged gestations or inaccuracies in gestational age at pregnancy diagnosis.

For the producer, these findings represent expected efficacy of the wellness trait predictions when animals enter production. This means that more accurate direct selection decisions regarding the wellness traits can be made at a much earlier age than was previously possible. Furthermore, it is reasonable to assume that the enrolled animals are representative of the population in the wellness traits genetic evaluation, as the median STA and standard deviation are similar or the same as that of genetic evaluation (mean STA of 100 with $\mathrm{SD}$ of 5 ). The median reliabilities for these traits reported in Table 4 represent a substantial advancement from indirect selection and are on par with average sire reliabilities reported previously (Parker Gaddis et al., 2014). The observed variation in the reliability estimates reflect the usage of non-AI sires ( $\mathrm{n}=174$ of 2,$875 ; 6 \%$ of animals included) and mixed breed parentage $(\mathrm{n}=58 ; 2 \%$ of animals included with breed base representation $<94 \%$ ).

\section{Relative Odds Between Genetic Groups}

Similar to the average disease incidence (marginal means), we found significant differences $(P<0.05)$ in the odds ratios between the worst and best genetic groups (Table 3). Through 305 DIM, the odds ratio between the worst and the best genetic groups ranged between 1.6 and 17.1 for lameness and displaced abomasum, respectively. For the remaining traits, retained placenta, metritis, mastitis, and ketosis, the odds ratios for the worst and best genetic groups were at least 2 , indicating that the relative odds of the animals in the worst genetic group to be affected by the disease was twice that of animals in the best genetic group (Table $3)$. 
Table 5. Disease incidence (marginal means) of the health events by age group (age group A: 2-yr-old cows; age group B: 3-yr-old cows) and lactation

\begin{tabular}{|c|c|c|c|c|c|c|}
\hline Health event & $\begin{array}{l}\text { Age } \\
\text { group }\end{array}$ & Lactation & df & $\begin{array}{l}\text { Marginal } \\
\text { mean }(\%)\end{array}$ & $\begin{array}{c}\text { SEM } \\
(\%)\end{array}$ & $P$-value \\
\hline \multirow[t]{3}{*}{ Retained placenta } & $\mathrm{A}$ & 1 & \multirow[t]{3}{*}{878} & $2.97^{\mathrm{a}}$ & 1.01 & \multirow[t]{3}{*}{0.2225} \\
\hline & B & 1 & & $2.19^{\mathrm{a}}$ & 0.82 & \\
\hline & B & 2 & & $3.30^{\mathrm{a}}$ & 1.12 & \\
\hline \multirow[t]{3}{*}{ Metritis } & $\mathrm{A}$ & 1 & \multirow[t]{3}{*}{872} & $25.80^{\mathrm{a}}$ & 4.81 & \multirow[t]{3}{*}{$<0.0001$} \\
\hline & B & 1 & & $22.71^{\mathrm{a}}$ & 4.55 & \\
\hline & B & 2 & & $9.74^{\mathrm{b}}$ & 2.36 & \\
\hline \multirow[t]{3}{*}{ Ketosis } & $\mathrm{A}$ & 1 & \multirow[t]{3}{*}{787} & $2.03^{\mathrm{a}}$ & 1.26 & \multirow[t]{3}{*}{0.6366} \\
\hline & $\mathrm{B}$ & 1 & & $1.94^{\mathrm{a}}$ & 1.23 & \\
\hline & B & 2 & & $2.36^{\mathrm{a}}$ & 1.48 & \\
\hline \multirow[t]{3}{*}{ Displaced abomasum } & $\mathrm{A}$ & 1 & \multirow[t]{3}{*}{694} & $0.19^{\mathrm{a}}$ & 0.13 & \multirow[t]{3}{*}{0.2918} \\
\hline & B & 1 & & $0.24^{\mathrm{a}}$ & 0.18 & \\
\hline & B & 2 & & $0.40^{\mathrm{a}}$ & 0.28 & \\
\hline \multirow[t]{3}{*}{ Mastitis } & $\mathrm{A}$ & 1 & \multirow[t]{3}{*}{725} & $9.65^{\mathrm{a}}$ & 1.87 & \multirow[t]{3}{*}{$<0.0001$} \\
\hline & B & 1 & & $6.33^{\mathrm{a}}$ & 1.42 & \\
\hline & $\mathrm{B}$ & 2 & & $22.96^{\mathrm{b}}$ & 3.87 & \\
\hline \multirow[t]{3}{*}{ Lameness } & A & 1 & \multirow[t]{3}{*}{651} & $9.09^{\mathrm{a}}$ & 3.02 & \multirow[t]{3}{*}{$<0.0001$} \\
\hline & $\mathrm{B}$ & 1 & & $6.13^{\mathrm{b}}$ & 2.18 & \\
\hline & B & 2 & & $12.84^{\mathrm{c}}$ & 4.18 & \\
\hline
\end{tabular}

${ }^{a-c}$ Marginal means within column and trait with different superscripts differ $(P<0.05)$.

\section{Quantification of Age Groups on the Associated Incidence of Health Events}

Quantifying the effects of the age group and lactation on the phenotypic incidence reveals that lactation appears to exert an appreciable effect on phenotypic incidence for metritis, mastitis, and lameness (Table 5). Further analysis of the marginal means from animals in age group A starting a second lactation versus animals that fail to start a second lactation would allow for quantification of effects of environmental selection bias between first and second parity. The effect of the interaction of age group with lactation on the disease incidence (marginal mean) for retained placenta, displaced abomasum, and ketosis was not significant $(P>$ 0.2 ; Table 5); in contrast, the effect of the interaction between age group and lactation was significant $(P<$ 0.0001 ) for the disease incidence (marginal means) of metritis, mastitis, and lameness (Table 5). Pairwise comparisons revealed that these differences were associated with specific lactations, as the incidence of metritis was higher in the first lactation compared with the second. The metritis observations in our study were similar to previous reports quantifying differences in the incidence of metritis across lactations, where first-lactation animals had a higher incidence for metritis than later lactation (Parker Gaddis et al., 2012; Vergara et al., 2014). The increase in the incidence of mastitis and lameness in the second lactation was also consistent with joint research conducted by North Carolina State University (Raleigh), Dairy Records Management Systems (Raleigh, NC), and the USDA Animal Genomics and Improvement Laboratory (Beltsville, MD; Parker
Gaddis et al., 2012). Using lactation records that would have previously been excluded from the analysis due to insufficient lactation length results in a more accurate association between the prediction and the adverse health event while minimizing selection bias of records (e.g., only complete lactations). Furthermore, this approach is consistent with the observed performance of the animals treated by dairy producers, as animals treated for mastitis at 20 DIM and subsequently sold at 50 DIM still incur costs associated with veterinary treatments, increased labor, and withheld milk.

\section{Incidence of Health Events, Genomic Relationship, and Average STA of Enrolled Animals}

The incidence of the health events in the enrolled herds for the first and second lactations depicted in Table 2 is similar to the incidence that have been previously reported (Zwald et al., 2004; Parker Gaddis et al., 2012; Vukasinovic et al., 2017). A possible explanation of the differences in incidence between our observations (e.g., $16.2 \%$ mastitis) and previous reports (e.g., $25 \%$ mastitis) may be due to differences in parity structure (Zwald et al., 2004; Parker Gaddis et al., 2012; Vukasinovic et al., 2017) and changes across time due to genetic or diagnostic and surveillance advancements (Zwald et al., 2004; Parker Gaddis et al., 2012; Vukasinovic et al., 2017).

Relative to the genetic evaluation population (n $\geq 250,000$ ), the average diagonal values of the $\mathbf{G}$ matrix for the study population $(\mathrm{n}=2,875)$ was 1.011 with a standard deviation of 0.031 . The $\mathbf{G}$ or the genomic relationship matrix can be described as a molecular as- 
sessment of how related an animal is to the animals within the genetic evaluation using genotypic information. A diagonal value of 1 indicates average connectivity to the population, with lower diagonal values representing higher connectivity to the population (animals with genotypes that are highly represented in the population) and higher diagonal values represent low connectivity to the population (Legarra et al., 2009; Aguilar et al., 2010; Simeone et al., 2011). Of the study population, $99.7 \%$ were within 3 standard deviations of the average genomic relationship for the genetic evaluation population ( $\mathrm{n}>250,000$ genotyped animals; $\mu=1.005, \sigma=0.037)$. The 8 animals that were more than 3 standard deviations from the mean were more distantly related to the genetic evaluation population. The similar genomic relationship observed between the study population $(\mu=1.011, \sigma=0.031)$ and the population in genetic evaluation $(\mu=1.005, \sigma=0.037)$ was expected, given that the genetic evaluation relies on genotypes, pedigree, and phenotypes collected on Holstein cows from dairies within the United States.

The genetic merit of the study population is similar in genetic makeup to the population in the genetic evaluation, as indicated by the observed median STA of 100 and 101 with a standard deviation at or close to 5 (Table 4). The average reliabilities are close to what was reported when herds contribute phenotypes to the genetic evaluation (Vukasinovic et al., 2017). The genetic composition of the 2 age groups (A, B) was similar as assessed by the median STA values, which ranged between 99 and 102 for each of the 6 traits. In addition, the standard deviations of the STA for each of the 6 traits ranged from 4.8 to 5.1. Notably, the median STA values of the genetic groups are similarly centered on 100, with the worst and the best genetic group separated by approximately 2 standard deviations (Table 6).

\section{Potential Use of STA to Enhance Predictive Algorithms}

The findings in our study may have important implications for shaping future research and modeling exercises where phenotypic performance is used to predict health events (Islam et al., 2013; Vergara et al., 2014; Smith et al., 2017). The information represented by the genomically enhanced STA can be used to improve the predictive capacity of such equations. The contribution of genetic and environment to predict the phenotype seems to be a reasonable approach when formulating predictive equations. A good example of integrating genetics and environmental information would be the predictive equations formulated by McArt et al. (2013), which could be coded into herd management systems to include additional information, such as ration formulation and season, to increase their relevance. Importantly, similar considerations could be made when designing experiments where the desired outcome is to reduce the incidence of the adverse health event ( $\mathrm{Du}-$ buc et al., 2011). Inclusion of the genomic predictions for adverse health events (e.g., wellness traits STA), either as a covariate with and without interaction with the treatment or blocking upon genetic potential, would potentially yield insights into the experimental design process (e.g., reducing bias) regarding genetic by management interactions.

\section{Comparison with Validation Approaches}

To the best of our knowledge, this is the first report demonstrating the efficacy of genomically enhanced wellness trait predictions in an independent external population of Holstein cows. For the present study, validation refers to the association between genomic predictions (STA) and observed performance (health outcomes) in Holstein cattle. Previously reported validation approaches performed in other studies used different methodologies emphasizing different objectives. Haugaard et al. (2015) reported gains in the accuracy (expressed as the square root of the reliability) for a genetic estimate once additional phenotypic data had

Table 6. Median standardized transmitting abilities (STA) values of the genetic groups for each of the 6 wellness traits

\begin{tabular}{llr}
\hline & $\begin{array}{l}\text { STA percentile } \\
\text { Trait }\end{array}$ & Median \\
& STA & \\
\hline RETP-STA & Bottom 25 & 94 \\
& $26-50$ & 99 \\
& $51-76$ & 103 \\
METR-STA & Top 25 & 106 \\
& Bottom 25 & 94 \\
& $26-50$ & 99 \\
KETO-STA & Top 25 & 102 \\
& Bottom 25 & 106 \\
& $26-50$ & 94 \\
DA-STA & $51-76$ & 100 \\
& Top 25 & 103 \\
& Bottom 25 & 106 \\
& $26-50$ & 95 \\
MAST-STA & $51-76$ & 100 \\
& Top 25 & 103 \\
& Bottom 25 & 106 \\
& $26-50$ & 93 \\
LAME-STA & $51-76$ & 98 \\
& Top 25 & 101 \\
& Bottom 25 & 105 \\
& $26-50$ & 93 \\
& $51-76$ & 98 \\
& Top 25\% & 101 \\
& & 106 \\
\hline
\end{tabular}

${ }^{1}$ Retained placenta (RETP-STA), metritis (METR-STA), ketosis (KETO-STA), displaced abomasum (DA-STA), mastitis (MASTSTA), and lameness (LAME-STA). 
been included in the genetic evaluation, which demonstrates the value of adding phenotypic information to the genetic evaluation. Additionally, validation of marker effects is a common practice in genomics research within breed and also when the validation breed is different from the reference breed. Cross validation with random assignment of records to the training and validation populations is a robust approach commonly employed when validating a genetic evaluation (Vazquez et al., 2012; Haugaard et al., 2013). However, this approach can fail to properly account for clustering of animals within herds, and it does not remove the inherent bias of the methodology when herds are allowed to contribute phenotypes and pedigree to both the training and validation populations. Quantifying the relationship between sire gPTA generated from a training data set and observed daughter performance in the validation training set (Parker Gaddis et al., 2015 ) is the methodology most similar to our approach, but such a strategy does not completely remove the bias present when herds contribute phenotypes to both training and validation data sets. The key difference between these referenced methodologies and our concept of external and independent validation is summarized in the objective of our study: demonstrate the ability of wellness trait predictions to accurately predict disease incidence using herds that do not contribute phenotypes to the genetic evaluation. Conceptually, in our approach the genetic evaluation phenotypes and the study population phenotypes are independent of each other, only connected by the DNA of the animals in the study and the pedigree information constructed from this genotypic information.

\section{CONCLUSIONS}

The results of this study provide evidence of the efficacy of the wellness traits genetic evaluation for the genomically enhanced genetic predictions for retained placenta, metritis, ketosis, displaced abomasum, mastitis, and lameness in first and second lactation. These results indicate that genomic data of young calves and heifers can be used to effectively predict future health performance. Improving health traits, commonly referred to as functional or wellness traits, through direct genetic selection presents a compelling opportunity for dairy producers to help manage disease incidence and improve profitability when coupled with sound management practices. The findings from our study coupled with previous research demonstrate the value of collecting and recording health events in commercial dairies. Efforts to implement a more comprehensive and standardized on-farm recording and surveillance of health events in dairy cattle would provide additional value and improve the efficiency of the genetic evaluation. Future efforts regarding the animals enrolled in this study will focus on the association of wellness trait predictions and health event incidence in subsequent lactations.

\section{ACKNOWLEDGMENTS}

The authors thank the management teams of the enrolled farms for access to their cows and production records, Zoetis field colleagues for their continued support in collecting phenotypes, and the editorial board, staff, and reviewers of the Journal of Dairy Science for their efforts performing peer review of this manuscript.

\section{REFERENCES}

Aguilar, I., I. Misztal, D. L. Johnson, A. Legarra, S. Tsuruta, and T. J. Lawlor. 2010. Hot topic: A unified approach to utilize phenotypic, full pedigree, and genomic information for genetic evaluation of Holstein final score. J. Dairy Sci. 93:743-752.

APHIS. 2009. Dairy 2007 Part V: Changes in Dairy Cattle Health and Management Practices in the United States, 1996-2007. Page 268. Animal and Plant Health Inspection Service, National Animal Health Monitoring System, USDA, Fort Collins, CO.

Cha, E., D. Bar, J. A. Hertl, L. W. Tauer, G. Bennett, R. N. González, Y. H. Schukken, F. L. Welcome, and Y. T. Gröhn. 2011. The cost and management of different types of clinical mastitis in dairy cows estimated by dynamic programming. J. Dairy Sci. 94:4476-4487.

Cha, E., J. A. Hertl, D. Bar, and Y. T. Gröhn. 2010. The cost of different types of lameness in dairy cows calculated by dynamic programming. Prev. Vet. Med. 97:1-8.

Dairy Cattle Reproduction Council. 2011. The Value of Uterine Health: The Diseases, the Causes and the Financial Implications. Dairy Cattle Reproduction Council, Dublin, OH.

Dohoo, I., W. Martin, and H. Stryhn. 2009. Veterinary Epidemiologic Research. 2nd ed. VER Inc. Charlottetown, PEI, Canada.

Dubuc, J., T. F. Duffield, K. E. Leslie, J. S. Walton, and S. J. Leblanc. 2011. Randomized clinical trial of antibiotic and prostaglandin treatments for uterine health and reproductive performance in dairy cows. J. Dairy Sci. 94:1325-1338.

Gaurd, C. 1999. Retained placenta. Causes and treatments. Adv. Dairy Technol. 11:81-86.

Gaurd, C. 2009. The costs of common diseases of dairy cattle. Accessed Sep. 2016. http://veterinarycalendar.dvm360.com/costs -common-diseases-dairy-cattle-proceedings.

Haugaard, K., M. Svendsen, and B. Heringstad. 2015. Information from later lactations improves accuracy of genomic predictions of fertility-related disorders in Norwegian Red. J. Dairy Sci. 98:49284933.

Haugaard, K., L. Tusell, P. Perez, D. Gianola, A. C. Whist, and B. Heringstad. 2013. Prediction of clinical mastitis outcomes within and between environments using whole-genome markers. J. Dairy Sci. 96:3986-3993.

Heriazon, A., M. Quinton, F. Miglior, K. E. Leslie, W. Sears, and B. A. Mallard. 2013. Phenotypic and genetic parameters of antibody and delayed-type hypersensitivity responses of lactating Holstein cows. Vet. Immunol. Immunopathol. 154:83-92.

Islam, R., H. Kumar, S. Nandi, and R. B. Rai. 2013. Determination of anti-inflammatory cytokine in periparturient cows for prediction of postpartum reproductive diseases. Theriogenology 79:974-979.

Jones, W. P., L. B. Hansen, and H. Chester-Jones. 1994. Response of health care to selection for milk yield of dairy cattle. J. Dairy Sci. $77: 3137-3152$. 
Kuhn, M. T., P. M. VanRaden, and J. L. Hutchison. 2004. Use of early lactation days open records for genetic evaluation of cow fertility. J. Dairy Sci. 87:2277-2284.

Legarra, A., I. Aguilar, and I. Misztal. 2009. A relationship matrix including full pedigree and genomic information. J. Dairy Sci. 92:4656-4663.

Lucy, M. C. 2001. Reproductive loss in high-producing dairy cattle: Where will it end? J. Dairy Sci. 84:1277-1293.

McArt, J. A., D. V. Nydam, and G. R. Oetzel. 2013. Dry period and parturient predictors of early lactation hyperketonemia in dairy cattle. J. Dairy Sci. 96:198-209.

McArt, J. A. A., D. V. Nydam, and M. W. Overton. 2015. Hyperketonemia in early lactation dairy cattle: A deterministic estimate of component and total cost per case. J. Dairy Sci. 98:2043-2054.

Miller, R. H., M. T. Kuhn, H. D. Norman, and J. R. Wright. 2008 Death losses for lactating cows in herds enrolled in Dairy Herd Improvement test plans. J. Dairy Sci. 91:3710-3715.

Misztal, I., A. Legarra, and I. Aguilar. 2009. Computing procedures for genetic evaluation including phenotypic, full pedigree, and genomic information. J. Dairy Sci. 92:4648-4655.

Misztal, I., A. Legarra, and I. Aguilar. 2014. Using recursion to compute the inverse of the genomic relationship matrix. J. Dairy Sci. 97:3943-3952.

Misztal, I., S. Tsuruta, I. Aguilar, A. Legarra, P. M. VanRaden, and T. J. Lawlor. 2013. Methods to approximate reliabilities in single-step genomic evaluation. J. Dairy Sci. 96:647-654.

Neuenschwander, T. F. O., F. Miglior, J. Jamrozik, O. Berke, D. F. Kelton, and L. R. Schaeffer. 2012. Genetic parameters for producer-recorded health data in Canadian Holstein cattle. Animal 6:571-578.

Parker Gaddis, K. L., J. B. Cole, J. S. Clay, and C. Maltecca. 2012. Incidence validation and relationship analysis of producer-recorded health event data from on-farm computer systems in the United States. J. Dairy Sci. 95:5422-5435.

Parker Gaddis, K. L., J. B. Cole, J. S. Clay, and C. Maltecca. 2014. Genomic selection for producer-recorded health event data in US dairy cattle. J. Dairy Sci. 97:3190-3199.

Parker Gaddis, K. L., F. Tiezzi, J. B. Cole, J. S. Clay, and C. Maltecca. 2015. Genomic prediction of disease occurrence using producerrecorded health data: A comparison of methods. Genet. Sel. Evol. 47:41.

R Core Team. 2015. R: A Language and Environment for Statistical Computing. R Foundation for Statistical Computing, Vienna, Austria.

Sargolzaei, M., J. P. Chesnais, and F. S. Schenkel. 2014. A new approach for efficient genotype imputation using information from relatives. BMC Genomics 15:478.
SAS. 2011. SAS System for Windows. 9.3 ed. SAS Institute Inc., Cary, $\mathrm{NC}$

Schutz, M. M. 1994. Genetic evaluation of somatic cell scores for United States dairy cattle. J. Dairy Sci. 77:2113-2129.

Simeone, R., I. Misztal, I. Aguilar, and A. Legarra. 2011. Evaluation of the utility of diagonal elements of the genomic relationship matrix as a diagnostic tool to detect mislabelled genotyped animals in a broiler chicken population. J. Anim. Breed. Genet. 128:386-393.

Smith, G. L., N. C. Friggens, C. J. Ashworth, and M. G. Chagunda 2017. Association between body energy content in the dry period and post-calving production disease status in dairy cattle. Animal 15:1-9.

Thompson-Crispi, K. A., M. Sargolzaei, R. Ventura, M. Abo-Ismail, F. Miglior, F. Schenkel, and B. A. Mallard. 2014. A genome-wide association study of immune response traits in Canadian Holstein cattle. BMC Genomics 15:559.

VanRaden, P. M., and E. J. H. Klaaskate. 1993. Genetic evaluation of length of productive life including predicted longevity of live cows. J. Dairy Sci. 76:2758-2764.

Vazquez, A. I., M. A. Perez-Cabal, B. Heringstad, M. Rodrigues-Motta, G. J. M. Rosa, D. Gianola, and K. A. Weigel. 2012. Predictive ability of alternative models for genetic analysis of clinical mastitis. J. Anim. Breed. Genet. 129:120-128.

Vergara, C. F., D. Döpfer, N. B. Cook, K. V. Nordlund, J. A. A. McArt, D. V. Nydam, and G. R. Oetzel. 2014. Risk factors for postpartum problems in dairy cows: Explanatory and predictive modeling. J. Dairy Sci. 97:4127-4140.

Vukasinovic, N., N. Bacciu, C. A. Przybyla, P. Boddhireddy, and S. K. DeNise. 2017. Development of genetic and genomic evaluation for wellness traits in US Holstein cows. J. Dairy Sci. 100:428-438.

Weigel, K. A., P. C. Hoffman, W. Herring, and T. J. Lawlor Jr. 2012 Potential gains in lifetime net merit from genomic testing of cows, heifers, and calves on commercial dairy farms. J. Dairy Sci. $95: 2215-2225$

Weigel, K. A., T. J. Lawlor, P. M. Vanraden, and G. R. Wiggans. 1998. Use of linear type and production data to supplement early predicted transmitting abilities for productive life. J. Dairy Sci. $81: 2040-2044$.

Zwald, N. R., K. A. Weigel, Y. M. Chang, R. D. Welper, and J. S. Clay. 2004. Genetic selection for health traits using producerrecorded data. I. Incidence rates, heritability estimates, and sire breeding values. J. Dairy Sci. 87:4287-4294.

Zwald, N. R., K. A. Weigel, Y. M. Chang, R. D. Welper, and J. S. Clay. 2006. Genetic analysis of clinical mastitis data from onfarm management software using threshold models. J. Dairy Sci. $89: 330-336$ 